\title{
Brood development into sexual females depends on the presence of a queen but not on temperature in an ant dispersing by colony fission, Aphaenogaster senilis
}

\author{
RAPHÄ̈L BOULAY ${ }^{1}$, XIM CERDÁ ${ }^{1}$, ARNOLD FERTIN², \\ KATS Y UA ICHINOSE ${ }^{3}$ and A L A IN LENOIR ${ }^{2}{ }^{1}$ CSIC, Estación Biológica de Doñana, \\ Seville, Spain, ${ }^{2}$ IRBI, CNRS UMR 6035, Université François Rabelais, Tours, France and ${ }^{3}$ KONARC, Nishigoshi, Kikuchi-gun, \\ Kumamoto-ken, Japan
}

\begin{abstract}
In eusocial insects, colony fission is a mode of dispersal by which a young queen leaves her nest with some workers to found a new colony. In these species, adult females (workers and the queen) should allocate most resources to increasing their colony size, which constrains the possibility of fission. In contrast, developing diploid larvae should have a preference for becoming a queen and having their own offspring, rather than becoming workers and rearing the offspring of other females.

2. In the ant Aphaenogaster senilis, queens are produced in very small numbers, suggesting that adult females control larval development. We used a 6-year series of data on more than 300 nests to determine the annual cycle of worker and queen production. Although both overlapped, the latter mostly occurred in the second half of the summer, after a major peak of worker emergence. Young queens were also often produced in nests whose reproductive queen had died, thus allowing her replacement. Overall, we estimate that only $0.07 \%$ of diploid larvae actually develop into gynes.

3. Laboratory experiments indicated that brood is bipotent until the second larval instar. Diploid larval development into queen was favoured by the removal of the mother queen, but was not affected by rearing temperature.

4. Our data suggest that most diploid broods are forced by the adults to develop into workers rather than into gynes. However, when the queen is not present due to death or after a fission event, a few larvae are allowed to develop into gynes. One way for workers to limit the development of larvae might be by controlling the amount of food they receive.
\end{abstract}

Key words. Brood rearing, brood totipotency, Caste determination, colony life cycle, queen pheromone, temperature, worker control.

\section{Introduction}

Although social insects are famous for their cooperative behaviour, their colonies are also the scene of important conflicts over reproduction (Ratnieks et al., 2006). For example, caste fate conflict opposes adults and immature females over the proportion of larvae that will eventually become gynes (virgin queens with a reproductive potential) or sterile workers. This conflict can be seen as a particular case of parent-offspring conflict that

Correspondence: Raphaël Boulay, Estación Biológica de Doñana, CSIC, Avenida Américo Vespucio 41092 Seville, Spain. E-mail: boulay@ ebd.csic.es potentially evolved in all animal species with parental care (Trivers, 1974; Clutton-Brock \& Parker, 1995). Although caste fate conflict might be ubiquitous to all eusocial hymenopterans, it is easily observed in species dispersing by colony fission (Ratnieks, 2001; Wenseleers et al., 2003). In these species, colonies are initiated by a young queen accompanied by a group of workers. Queens are thus protected throughout their life, which enormously decreases their mortality compared with species in which queens start colonies alone (independent foundation). However, the workers that leave the mother nest represent an important investment, which limits fission events (Pamilo, 1991; Peeters \& Ito, 2001). Thus, from the adult workers and the queen's viewpoint, overproducing gynes represents a waste of 
energy, and effort should rather be devoted chiefly to increasing colony size. In contrast, any developing female may expect a higher fitness by becoming a queen and having her own offspring, with which she will be more closely related than with those of other females (Nonacs \& Tobin, 1992; Bourke \& Franks, 1995; Bourke \& Ratnieks, 1999; Ratnieks, 2001; Wenseleers et al., 2003).

Theoretical models suggest that if diploid larvae controlled their own development, 14-20\% would develop into gynes. However, with the exception of a few stingless bees (Kerr, 1950, 1969; Engels \& Imperatriz-Fonseca, 1990; Wenseleers et al., 2003), gyne production in most fission-performing species is extremely limited [e.g. $0.01 \%$ of the diploid brood in the honeybee Apis mellifera (Seeley, 1985; Winston, 1987), 0.001\% in the army ant Eciton burchelli (Schneirla, 1971; Franks \& Hölldobler, 1987)]. One explanation is that the adults-larvae conflict cannot be expressed, because larvae lack control over their own development. Determination of the proximate (physiological and ecological) mechanisms affecting caste determination and its social regulation, therefore seems necessary in understanding conflict resolution.

Until recently, the development of diploid brood into worker or gyne was thought to depend mainly on environmental conditions (Wheeler, 1986, 1994). For example, honey bee larvae developing into gynes receive a special food, royal jelly, which may trigger caste differentiation (Moritz, 1994). In ants, caste development has long been shown to differ according to larval food (Bonavita-Cougourdan \& Passera, 1978) and rearing temperature (Brian, 1973; Ledoux, 1977; Cassill \& Tschinkel, 2000). Therefore, by providing food and moving the larvae up and down temperature gradients within the nest, workers might directly control gyne production.

The queen may also have power over gyne production. In numerous species, her removal triggers gyne development and it has been hypothesised that she releases pheromones that indirectly affect diploid brood development by changing worker rearing behaviour (Passera, 1980; Vargo \& Fletcher, 1986; Winston et al., 1990; Pereboom, 2000; Boulay et al., 2007). Direct coercion through the emission of primer pheromones is another way in which queens might force caste development. However, this mechanism still lacks evidence and is evolutionarily questionable (Keller \& Nonacs, 1993). Finally, maternal effects (Gösswald \& Bier, 1954; Passera \& Suzzoni, 1978; de Menten et al., 2005; Schwander et al., 2008) and genetic caste determination have recently been identified (Tsuji \& Yamauchi, 1995; Pearcy et al., 2004; Fournier et al., 2005), suggesting that, in some species, diploid brood development might be fixed even before egg hatching (Helms, 1999; Duchateau et al., 2004; Iwanishi et al., 2007).

Aphaenogaster senilis is an ant species that disperses by colony fission. In a former paper, Boulay et al. (2007) have shown that gynes of this species are most often discovered either in naturally queenless nests or in large queenright nests (i.e. containing a fertile queen). These authors also found that the separation of a group of workers and brood from the mother colony through a double mesh did not prevent the production of new gynes. In contrast, when the separation was made of a single mesh, the production of new gynes was reduced. It was 
therefore hypothesised that the queen $A$. senilis releases chemicals that diffuse into the colony and inhibit the differentiation of diploid brood into gynes. In nature, gynes would be produced when the concentration of the queen pheromone in the colony drops below a certain threshold, either because the mother queen dies, which allows her replacement, or because the colony is large enough to permit fission (Boulay et al., 2007). This scenario assumes that larvae are bipotent (i.e. they can potentially develop into either castes) until a certain instar, but this may not necessarily be the case. Although it is unlikely, gyne production in the absence of the queen may not derive from the reorientation of bipotent larvae, but from worker thelytoky (i.e. the production of diploid offspring by parthenogenesis), as in a few other ant species (Lenoir \& Cagniant, 1986; Tsuji, 1988; Tsuji \& Yamauchi, 1995).

In the present study, we tested the hypothesis that $A$. senilis gyne derive from bipotent larvae. To this aim, we first had to determine the number of larval instars. Second, we analysed colony demography in nature in order to determine whether the production of gynes and workers followed an annual cycle and if both castes could potentially derive from the same brood. We also estimated the proportion of diploid larvae that develop into gynes. Finally, we conducted a series of lab experiments to test gyne production after orphaning with different brood stages and as a function of rearing temperature.

\section{Materials and methods}

\section{Model system}

Aphaenogaster senilis is a strictly monogynous ant species distributed around the Western Mediterranean basin (Cagniant \& Ledoux, 1974). Monomorphic workers are 6-10 mm in body length (unpubl. data). They are particularly abundant in the south of the Iberian Peninsula, in sandy biotopes such as the Doñana National Park where our colonies were collected. Climate in this region is typically Mediterranean with cool winters and hot, dry summers.

\section{Larval development}

In order to determine the number of larval instars of $A$. senilis, five colonies were excavated in May-June 2002. They were kept for a few months in the lab at $28{ }^{\circ} \mathrm{C} \pm 1{ }^{\circ} \mathrm{C}$ with ad libitum access to water and food (maggots and $20 \% \mathrm{v} / \mathrm{v}$ honey solution). All the brood was then collected and the maximum width of all larvae was measured using a stereomicroscope. After determining the distribution of larval size, larval instars were confirmed by examining the morphology and size of mandibles and hairs of 20 larvae of each mode under the microscope (Passera, 1974).

\section{Annual cycle of brood and gyne production}

A total of 308 colonies were excavated between December 2002 and September 2008. Brood and workers were then sorted 
out to determine the presence of a dealated queen, the number of gynes (pupae and adults), the fresh biomass of workers, of eggs + LI larvae, LII + LIII larvae, worker pre-pupae, and worker pupae. We also counted the number of worker pupae.

\section{Effect of larval stage and temperature on gyne production}

Twenty medium-sized freshly collected colonies were divided to form a total of 100 orphan groups of 200 workers, kept in artificial nests composed of a $2 \times 20$-cm (diameter $\times$ length) glass tube half-filled with water and connected to a $9 \times 7-\mathrm{cm}$ (diameter $\times$ height) foraging area, the internal wall of which was painted with Fluon to prevent ants escaping. Each worker group was provided with 20 eggs, 20 LI larvae, 20 LII larvae, 20 LIII larvae, or no brood at all. All groups were kept at $28^{\circ} \mathrm{C} \pm 1{ }^{\circ} \mathrm{C}$ in complete darkness and fed every second day with three Tenebrio molitor worms cut into small pieces. The presence of gyne and worker pupae was checked every second day for 42 days.

In a second experiment, 26 freshly collected colonies were divided in 60 orphan groups of 200 workers with 20 eggs, 20 LI larvae, 20 LII larvae, or 20 LIII larvae. Twenty groups were kept at $24^{\circ} \mathrm{C} \pm 1{ }^{\circ} \mathrm{C}, 20$ groups at $27^{\circ} \mathrm{C} \pm 1{ }^{\circ} \mathrm{C}$, and 20 groups at $30{ }^{\circ} \mathrm{C} \pm 1{ }^{\circ} \mathrm{C}$ in complete darkness, and fed every second day with mealworms. The presence of gyne and worker pupae was checked every second day for 42 days.

\section{Statistics}

All statistics were conducted using the free environment software R (R Core Team, 2008). Seasonal variations in a response variable $(\mathrm{Y})$ can be modelled linearly as $\mathrm{Y}=\mathbf{a}+$ p.sin(2.u. time) $+\mathrm{y} \cdot \cos (2 . u \cdot$ time $)+\mathrm{c}$ where a, p, y, and c are model parameters and time is an annual index, so that 365.25 days is given a unit value (Crawley, 2002). Therefore, annual cycle in brood and worker biomass was tested by fitting a linear regression model to the data with $\sin (2$.u.time) and $\cos (2 . u . t i m e)$ as independent variables. Brood and worker biomass were square root transformed to approach normality. The probability of discovering a gyne in a nest in nature was modelled using a binomial regression and the logit link function. Explanatory variables included in the initial model were sin(2.u.time) and $\cos (2 . u . t i m e)$, plus the presence of a queen in the colony, the biomass of workers, the biomass of brood, and their interactions. Non-significant interactions and variables were then progressively removed until the most parsimonious model was obtained based on an analysis of deviance (Crawley, 2002). A similar backward procedure was used to model the delay (number of days) until the production of the first pupa of worker and gyne in the laboratory as a function of brood stage and temperature. In this analysis, data collected on groups coming from the same source colonies did not constitute independent observations. Therefore, the source colony was included as a random factor in generalised linear models that were fitted using the lme4 package for R (Bates et al., 2008). Although this function does not provide $P$-values for a single random factor, it takes it into account to estimate the effect of the fixed factors on the response. In this case, most adequate model selection is based on a $y^{2}$ statistics. The response variable was the number of days until pupa production, divided by 42 , the maximum duration of the experiment. This ratio was modelled using a binomial distribution and Logit link function. Explanatory variables were the caste of the pupa (worker vs. gyne) and either the brood stage that was initially offered or the rearing temperature $\left(24^{\circ} \mathrm{C}, 27^{\circ} \mathrm{C}\right.$, or $\left.30^{\circ} \mathrm{C}\right)$.

\section{Results}

\section{Larval development}

Measurement of the maximum width of 1058 larvae and examination of mandibular morphology and hair structure revealed that the development of $A$. senilis workers is formed by six successive pre-imago stages that include eggs, three larval instars, a pre-pupa, and a pupa stage (Electronic appendices 1-3).

\section{Annual cycle of brood and gyne production}

The total biomass of brood and adult workers varied significantly throughout the year (Table 1 and Fig. 1a). In winter (December to February), brood was chiefly composed of eggs and LI that were clumped together in deep nest chambers (Fig. 1b). In spring, brood biomass increased enormously with the successive appearance of LII, LIII, pre-pupae, and pupae, whereas workers from the previous cohort progressively died leading to a slight decrease in total worker biomass. This trend was reversed in May with the emergence of the first workers and consecutive decrease in brood biomass. Worker biomass was the highest in mid-summer, but decreased notably from the second half of August onwards. Colony composition then remained quite stable until the following spring.

Of the 308 nests that were excavated between December 2002 and September 2008, only 18 contained gynes (either at

Table 1. Results of the linear regression testing for worker and brood biomass time dependence.

\begin{tabular}{|c|c|c|c|c|c|c|c|c|}
\hline & \multicolumn{4}{|c|}{ Worker biomass } & \multicolumn{4}{|c|}{ Brood biomass } \\
\hline & Estimate & $\mathrm{SE}$ & $t$ & $P$ & Estimate & $\mathrm{SE}$ & $t$ & $P$ \\
\hline Intercept & 2.51 & 0.04 & 64.70 & $<0.001$ & 1.14 & 0.04 & 31.43 & $<0.001$ \\
\hline $\sin$ (2.u.time) & -0.12 & 0.05 & -2.16 & 0.032 & 0.46 & 0.05 & 9.00 & $<0.001$ \\
\hline $\cos (2 . u . t i m e)$ & -0.03 & 0.05 & -0.64 & 0.520 & -0.41 & 0.05 & -7.94 & $<0.001$ \\
\hline
\end{tabular}



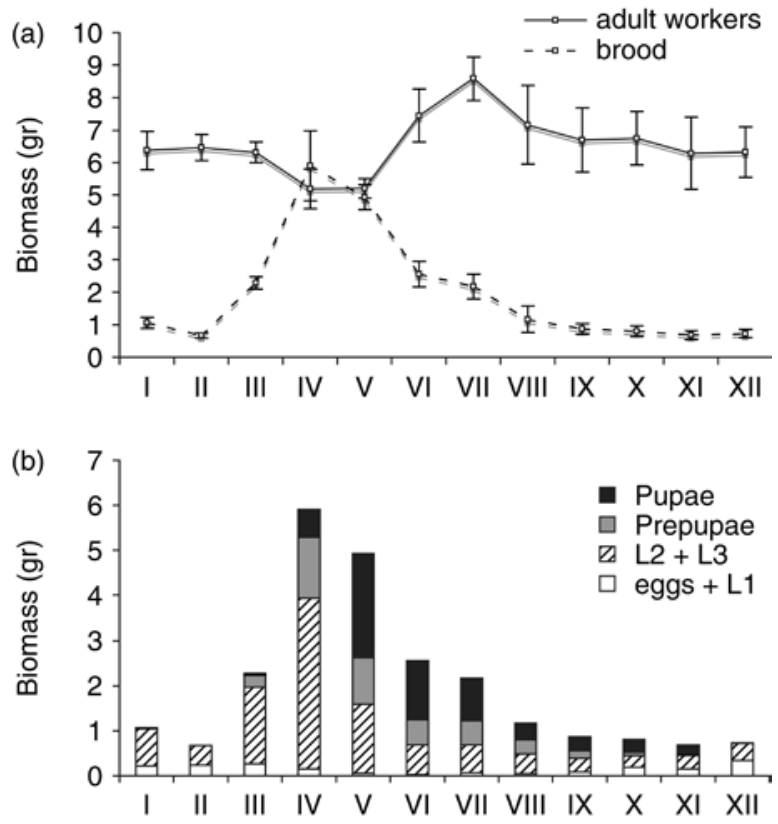

(c)

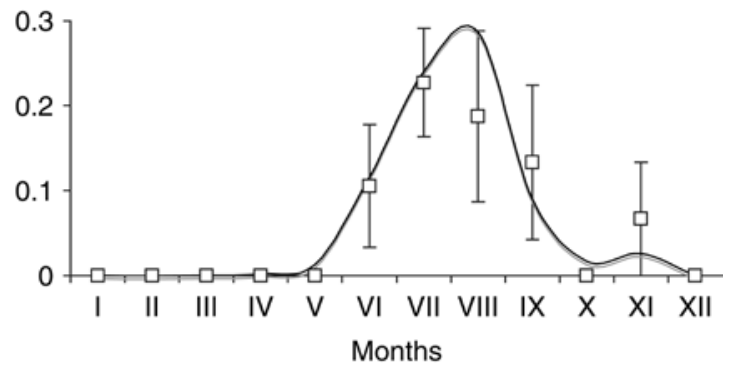

Fig. 1. Annual cycle of Aphaenogaster senilis nest demography in the field: (a) variation of total brood and worker biomass (values are means $\pm \mathrm{SE}$ ); (b) variation of brood composition (values are cumulated means); (c) probability of production of at least one gyne (squares and error bars are means \pm SE while the line represents the expected values generated by the most adequate model - see Table 2 for details).

the pupa or adult stage). Gynes were in any case produced in very small numbers, not exceeding six individuals per colony. In total, 28 gynes were encountered (14 of which were still pupae; mean \pm SE: $0.04 \pm 0.01$ gyne pupa per nest). These nests contained, on average, $57.88 \pm 6.95$ worker pupae. This gives a rough estimate of $0.07 \%$ [0.04/(57.88 + 0.04)] diploid larvae developing into gyne.

Table 2 summarises the result of model selection for the probability of the presence of at least one gyne in nature. Gyne production followed a marked annual pace $[t=-2.89, P=0.004$ and $t=-2.73, P=0.006$ for $\sin (2 . u$.time) and $\cos (2$. u.time), respectively] and in mid-summer one gyne was found in up to $30 \%$ of the nests (Fig. 1c). Gyne production was more frequent in queenless than in queenright nests (38\% vs 5\%, respectively; $t=4.36, P<0.001)$ and increased with worker biomass ( $t=3.17, P<0.001)$. However, it was not significantly related to brood biomass (Table 2).

\section{Effect of brood stage and temperature on larval development}

Laboratory experiments revealed that the time until the production of the first pupa in orphan groups depended on the brood instar that was initially provided (Table 3, Fig. 2). The most adequate model fitted to the data included the interaction between brood stage and the caste of the pupa produced. In effect, if no brood was initially provided, no gyne or worker pupa was produced. If only LIII larvae were provided, worker pupae were produced in all the nests in approximately 13 days, but no gyne pupa appeared by 42 days. Gyne pupae were only produced if eggs, LI or LII were provided. In no case were more than three gynes produced per group. Workers in all orphaned groups apparently laid eggs. In the brood-deprived groups, eggs started hatching after 35 days and by day 42, most orphan groups had a few small larvae. We could not follow their subsequent development. It is therefore difficult to tell whether egg incubation is particularly long in this species (35 days) or whether the first worker-laid eggs were policed by other workers.

Temperature also affected pupae production (Table 4, Fig. 3). At $30{ }^{\circ} \mathrm{C}$, pupae production was much faster than at $24^{\circ} \mathrm{C}$ and, on average, gynes took longer to be produced than workers. Nevertheless, there was no significant interaction between temperature and caste, indicating that in this temperature window, the delay between gyne and worker production was independent of rearing temperature.

\section{Discussion}

Morphological data suggest $A$. senilis has three larval instars, which is also the case in other Myrmicine ants (Weir, 1959;

Table 2. Results of model selection for gyne production $(\mathrm{G})$ in nature as a function of the presence of a queen (Q), worker biomass (W), and brood biomass (B). The most adequate model is shown in bold.

\begin{tabular}{|c|c|c|c|c|}
\hline Models & AIC & d.f. & Deviance & $P$ \\
\hline $\mathrm{G}=\mathrm{Q}+\sin (2 . \mathrm{u} \cdot \mathrm{time})+\cos (2 . \mathrm{u} \cdot \mathrm{time})$ & 80.8 & & & \\
\hline $\mathbf{G}=\mathbf{Q}+\mathbf{W}+\sin (2$. u.time $)+\cos (2$. u.time $)$ & 68.99 & 1 & 13.812 & 0.001 \\
\hline $\mathrm{G}=\mathrm{Q} \cdot \mathrm{W}+\sin (2 . \mathrm{u}$.time $)+\cos (2 . \mathrm{u} \cdot \mathrm{time})$ & 67.86 & 1 & 3.131 & 0.077 \\
\hline $\mathrm{G}=\mathrm{Q} \cdot \mathrm{W}+\mathrm{Q} \cdot \mathrm{B}+\sin (2 . \mathrm{u} . \mathrm{time})+\cos (2$. u.time $)$ & 69.26 & 2 & 2.602 & 0.272 \\
\hline $\mathrm{G}=\mathrm{Q} \cdot \mathrm{W}+\mathrm{Q} \cdot \mathrm{B}+\mathrm{W} \cdot \mathrm{B}+\sin (2$. u.time $)+\cos ($ 2.u.time $)$ & 70.16 & 1 & 1.103 & 0.294 \\
\hline $\mathrm{G}=\mathrm{Q} \cdot \mathrm{W} \cdot \mathrm{B}+\sin (2 \cdot \mathrm{u} \cdot \mathrm{time})+\cos (2 . \mathrm{u} . \mathrm{time})$ & 72.08 & 1 & 0.071 & 0.790 \\
\hline
\end{tabular}


Table 3. Results of model selection fitting the number of days (D) until pupa production in laboratory conditions as a function of larval stage (S) and caste (C) of the produced pupa. The minimum adequate model, in bold, includes the interaction between $\mathrm{C}$ and $\mathrm{S}$.

\begin{tabular}{lrllll}
\hline Models & d.f. & AIC & $\mathrm{y}^{2}$ & $\mathrm{y}^{2}$ d.f. & $P$ \\
\hline $\mathrm{D}=\mathrm{S}+\mathrm{C}$ & 7 & 65.785 & & & \\
$\mathbf{D}=\mathbf{S}+\mathbf{C}+\mathbf{S . C}$ & $\mathbf{1 1}$ & $\mathbf{5 9 . 8 0 3}$ & $\mathbf{1 4 . 2 6 3}$ & $\mathbf{4}$ & $\mathbf{0 . 0 0 7}$ \\
\hline
\end{tabular}

Bruder \& Gupta, 1972; Passera, 1974). Until the second instar, A. senilis larvae can develop into either gynes or workers, depending on the social environment. In the laboratory, gyne production almost never happens in the presence of the queen (Boulay et al., 2007). However, her experimental removal was rapidly followed by the development of one or a few gynes, provided that young brood (eggs, LI, or LII) was present. Neither workers nor gynes were produced if no brood was present at the time of orphaning. This indicates that gynes produced in orphan conditions derive from young bipotent larvae that would otherwise develop into workers. Workers have active ovaries and, in our experiments, they laid a few eggs. However, no egg hatched before 35 days, either because of a long incubation time or because workers eliminated the first worker-laid eggs. In both cases, the first worker-laid eggs hatched long after the first pupae occurred (only 12 days in LII-groups), which rules out worker thelytoky as a mechanism of gyne production, as this occurs in Cataglyphis cursor, Pristomyrmex pungens, and Cerapachys biroi (Lenoir \& Cagniant, 1986; Tsuji, 1988; Tsuji \& Yamauchi, 1995). In the present experiment, worker-laid eggs more likely yielded males as male production was shown to increase after about 3 months of orphaning (Boulay et al., 2007).

A kin selection theory suggests that if diploid larvae were able to decide their own development, a large proportion of them would develop into gynes. Ratnieks (2001) estimated this proportion to be between $14 \%$ and $20 \%$, which approaches gyne production in some Melipona bees in which larvae seem to have an important power on their development (Kerr, 1950, 1969; Engels \& Imperatriz-Fonseca, 1990; Wenseleers et al., 2003). In contrast, we estimated that in A. senilis, approximately $0.07 \%$

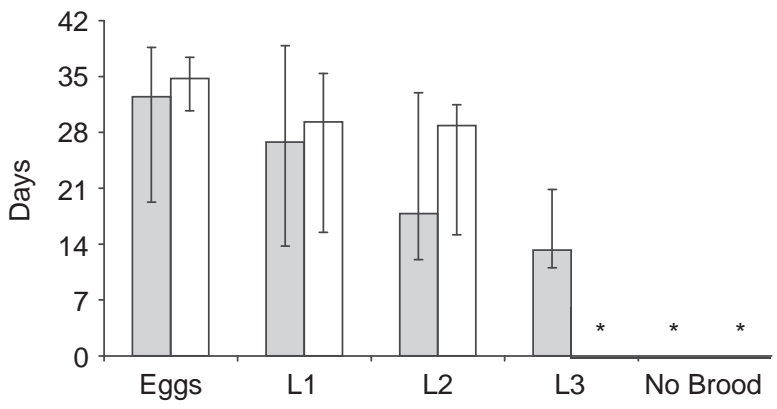

Fig. 2. Effect of brood stage on the time until the production of workers (grey bars) and gynes (white bars) in a queenless environment. The experiment lasted 42 days. Values are estimates (means \pm SE) calculated from the most adequate model (Table 3 ). *No gyne or worker was produced when no brood was initially provided. No gyne was produced when LIII were only provided.
Table 4. Results of model selection fitting the number of days (D) until pupa production in laboratory conditions as a function of rearing temperature ( $\mathrm{T}$ ) and caste $\mathrm{C}$ of the produced pupa. The minimum adequate model, in bold, includes simple main effects only.

\begin{tabular}{llllll}
\hline Models & d.f. & AIC & $\mathrm{y}^{2}$ & $\mathrm{y}^{2}$ d.f. & $P$ \\
\hline $\mathrm{D}=\mathrm{T}$ & 3 & 26.001 & & & \\
$\mathbf{D}=\mathbf{T}+\mathbf{C}$ & $\mathbf{4}$ & $\mathbf{2 2 . 6 4 6}$ & $\mathbf{5 . 3 5 4 6}$ & $\mathbf{1}$ & $\mathbf{0 . 0 2 0 7}$ \\
$\mathrm{D}=\mathrm{T}+\mathrm{C}+$ T.C & 5 & 22.451 & 2.1955 & 1 & 0.1384 \\
\hline
\end{tabular}

of the larvae develop into gynes. This is in the same order of magnitude as in the honeybee, in which $0.01 \%$ of diploid lavae develop into gynes (Seeley, 1985; Winston, 1987) and is one order of magnitude higher than in the army ant Eciton burchelli, in which $0.001 \%$ of the diploid brood may become gynes (Schneirla, 1971; Franks \& Hölldobler, 1987). Such a small percentage of diploid brood developing into gynes suggests their development is mostly controlled by the adult females.

The fact that only workers but no gyne were produced in queenless conditions if only LIII were provided, indicates that a critical period exists during which larvae can adopt the worker or gyne development pathways (Wheeler, 1986). However, the proximate mechanisms by which the presence of a queen determines the switch from worker to gyne route are still elusive. Previous results have shown that a group of workers and larvae separated from their mother queenright colony through a single mesh readily starts producing gynes. In contrast, a double-mesh separation between the orphan and the queenright group does not fully inhibit gyne production (Boulay et al., 2007). This suggests that a contact, queen-derived signal suppresses gyne production. However, theory predicts that queen pheromones are unlikely to act coercively on larval development (Keller \& Nonacs, 1993). Therefore, it is more probable that the queen signal affects the behaviour of workers who have more control on brood development. It was hypothesised that while $A$. senilis workers perceive the presence of their queen, they only allow worker development. However, when the queen signal fades out

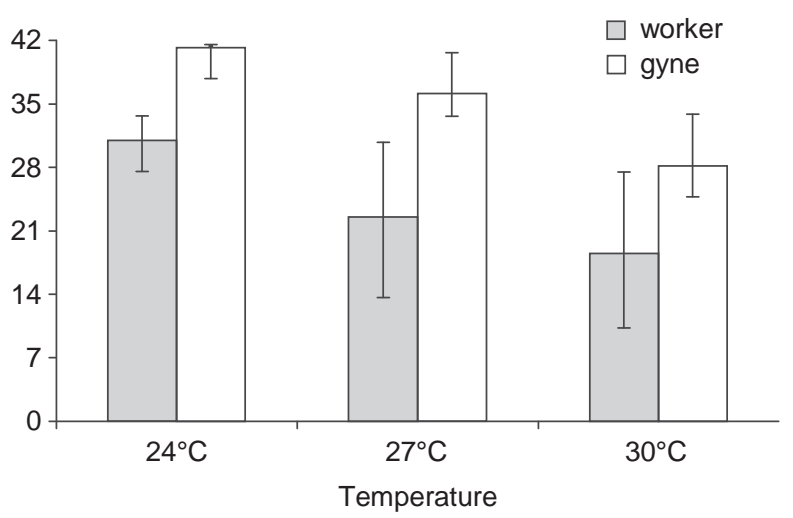

Fig. 3. Effect of temperature on the time until worker and gyne production in a queenless environment. Although pupation occurs more rapidly at a warm temperature, there is no significant interaction between temperature and caste development. Values are estimates (means $\pm \mathrm{SE}$ ) calculated from the most adequate model (Table 4). 
they start producing queens (Boulay et al., 2007). It was also hypothesised that in nature gyne production can occur when the queen dies, when a colony splits during a migration event or when a colony becomes sufficiently populated, so that the putative queen signal dilutes among the numerous workers, who then decide to rear one or a few gynes (Boulay et al., 2007). The present field data lend credence to the later scenario. In effect, although gynes are somehow rare throughout the year, they are more frequent at the end of July, when they can be found in up to $30 \%$ of the nests. This is just after the peak of worker emergence when colonies contain many young workers and still a relatively abundant brood. Relying on the concentration of a queen signal may be adaptive for the colony, because it allows the investment of energy in gyne production only when colony fission is sustainable or after the queen dies.

At our study site, air temperature varies in summer between $10{ }^{\circ} \mathrm{C}$ at dusk and $45^{\circ} \mathrm{C}$ in the afternoon (temperature data are available since 1978 at: www.ebd.csic.es/). Automatic temperature measurement indicates that temperature within the nests ranges from $20^{\circ} \mathrm{C}$ at $50 \mathrm{~cm}$ deep to $53^{\circ} \mathrm{C}$ in the most superficial chambers (R. Boulay \& F. Amor, unpubl. data). By moving the larvae within the nest, workers can determine their rearing temperature. Our results indicate that relatively warm temperatures actually increase the rate of pupation. Nevertheless, they give little support to the hypothesis that workers use temperature gradient to orient larval development into gyne or worker. In effect, increasing temperature equally affects the timing of gynes and worker production, which is apparently dissimilar to other species like Myrmica rubra (Brian, 1973) and Solenospis invicta (Cassill \& Tschinkel, 2000).

Differential feeding has long been proposed as a mechanism by which workers of social hymenopterans orientate larval development (Buschinger, 1990; Moritz, 1994; Wheeler, 1994) (Pereboom, 2000; Pereboom et al., 2003). Our experimental design did not allow us to test this effect and equal food access was provided to all colonies. In A. senilis, workers do not nourish larvae through trophallaxis and they therefore have little opportunity to transform larval food quality with salivary secretions (as in the honeybee, for example). Instead, workers generally transport larvae on the prey, allowing them to eat actively. On the other hand, workers that perceive the presence of the queen might control the time each larva spends feeding on the prey. By doing so, workers may have the power to force larval development into workers and to limit the allocation of energy to the production of a very small number of gynes required in a species that disperses by colony fission. Further studies are now needed to test this hypothesis.

Our data suggest that almost all $A$. senilis larvae are forced by adults to develop into workers rather than into gynes. This raises the question of why larvae do not intend to resist this coercion. Small gynes have been described together with normal large gynes in stingless bees (Wenseleers et al., 2005; Ribeiro et al., 2006) and in several ants of the genus Leptothorax (Rüppell et al., 1998), Ectatomma (Hora et al., 2005) and Manica (Lenoir et al., in press). The evolution of microgynes might be a mechanism for diploid larvae to become worker-like queens in spite of the vigilance of the adults (Wenseleers et al., 2005). In A. senilis, all queens are monomorphic and no such microgyne has been described. It has been proposed that the lack of larval resistance to adult power in many species is due to the fact that smaller individuals would be less fertile than normal large queens (Wenseleers et al., 2004). In the case of a monogynous, monandrous species like $A$. senilis, helping to rear numerous highly related sisters may then be more advantageous than having a small direct offspring. Moreover, in fission-performing species, the success of a queen is conditioned by the choice of workers that eventually decide when and which queen should leave the mother nest. In such a competitive context, workers may systematically prefer large highly fertile queens and ignore small individuals. Further comparative studies should help test these hypotheses. However, we still lack basic information from a large number of species to determine the relation between queen morphology and number, social organization and mode of dispersal.

\section{Acknowledgements}

We are grateful to Luc Passera and Claudie Doums who provided interesting comments on a previous version of the manuscript and to Isabel Luque Romero and Ana Carvajal Maldonado for their assistance in the field and the laboratory. We also thank the authority of the Doñana National Park for approving this research. Our work was funded by the Spanish Ministry for Education and Science project \# CGL2006-04968/BOS and FEDER to X.C. and R.B. All experiments conducted in this study comply with current Spanish legislation.

\section{References}

Bates, D., Maechler, M. \& Dai, B. (2008) Ime4: Linear Mixed-Effects Models Using S4 Classes [WWW document]. URL http://lme4. r-forge.r-project.org/.

Bonavita-Cougourdan, A. \& Passera, L. (1978) Étude comparative au moyen d'or radio-actif de l'alimentation des larves d'ouvrières et des larves de reine chez la fourmi Plagiolepis pygmaea Latr. Insectes Sociaux, 25, 276-287.

Boulay, R., Hefetz, A., Cerdá, X., Devers, S., Francke, W., Twele, R. et al. (2007) Production of sexuals in a fission-performing ant: dual effects of queen pheromones and colony size. Behavioral Ecology and Sociobiology, 61, 1531-1541.

Bourke, A.F.G. \& Franks, N.R. (1995) Social Evolution in Ants. Princeton University Press, Princeton, New Jersey.

Bourke, A.F.G. \& Ratnieks, F.L.W. (1999) Kin conflict over determination in social Hymenoptera. Behavioral Ecology and Sociobiology, 46, 287-297.

Brian, M.V. (1973) Temperature choice and its relevance to brood survival and caste determination in the ant Myrmica rubra L. Physiological Zoology, 46, 245-252.

Bruder, K.W. \& Gupta, A.P. (1972) Biology of the pavement ant, Tetramorium caespitum (Hymenoptera: Formicidae). Annals of the Entomological Society of America, 65, 358-367.

Buschinger, A. (1990) Regulation of worker and queen formation in ants with special reference to reproduction and colony development. Social Insects: An Evolutionary Approach to Castes and Reproduction (ed. by W. Engels), pp. 37-57. Springer-Verlag, Berlin, Heidelberg, Germany. 
Cagniant, H. \& Ledoux, A. (1974) Nouvelle description d'Aphaenogaster senilis sur des exemplaires de la région de Banyuls-sur-Mer (P.-O.), France. Vie Milieu Série C, 24, 97-110.

Cassill, D.L. \& Tschinkel, W.R. (2000) Behavioral and developmental homeostasis in the fire ant, Solenopsis invicta. Journal of Insect Physiology, 46, 933-939.

Clutton-Brock, T.H. \& Parker, G.A. (1995) Punishment in animal societies. Nature, 373, 209-216.

Crawley, M.J. (2002) Statistical Computing: An Introduction to S-Plus. Wiley, Chichester, U.K.

de Menten, L., Fournier, D., Brent, C., Passera, L., Vargo, E.L. \& Aron, S. (2005) Dual mechanism of queen influence over sex ratio in the ant Pheidole pallidula. Behavioral Ecology and Sociobiology, 58, 527-533.

Duchateau, M.J., Velthuis, H.H.W. \& Boomsma, J.J. (2004) Sex ratio variation in the bumblebee Bombus terrestris. Behavioral Ecology, 15, 71-82.

Engels, W. \& Imperatriz-Fonseca, V.L. (1990) Caste development, reproductive strategies, and the control of fertility in honey bees and stingless bees. Social Insects: An Evolutionary Approach to Castes and Reproduction (ed. by W. Engels), pp. 167-230. Springer-Verlag, Berlin, Heidelberg, Germany.

Fournier, D., Estoup, A., Orivel, J., Foucaud, J., Jourdan, H., Le Breton, J. et al. (2005) Clonal reproduction by males and females in the little fire ant. Nature, 435, 1230-1234.

Franks, N.R. \& Hölldobler, B. (1987) Sexual competition during colony reproduction in army ants. Biological Journal of the Linnean Society, 30, 229-243.

Gösswald, K. \& Bier, K. (1954) Untersuchungen zur Kastendetermination in der Gattung Formica. 3. Die Kastendetermination von Formica rufa rufo-pratensis minor Gossw. Insectes Sociaux, 1, 229-246.

Helms, K.R. (1999) Colony sex ratios, conflict between queens and workers, and apparent queen control in the ant Pheidole desertorum. Evolution, 53, 1470-1478.

Hora, R.R., Doums, C.C.P., Fénéron, R., Valenzuela, J., Heinze, J. \& Fresneau, D. (2005) Small queens in the ant Ectatomma tuberculatum: a new case of social parasitism. Behavioral Ecology and Sociobiology, 59, 285-292.

Iwanishi, S., Shin, S. \& Ohkawara, K. (2007) Biasing mechanisms for the sex investment ratio in the monogynous and monandrous ant Aphaenogaster smythiesi japonica Forel. Ethology Ecology \& Evolution, 19, 275-289.

Keller, L. \& Nonacs, P. (1993) The role of queen pheromones in social insects: queen control or queen signal? Animal Behaviour, 45, 787-794.

Kerr, W.E. (1950) Genetic determination of castes in the genus Melipona. Genetics, 35, 143-152.

Kerr, W.E. (1969) Some aspects of the evolution of social bees (Apidae). Evolutionary Biology, Vol. 3, pp. 119-175. Appleton-Century Crofts, New York.

Ledoux, A. (1977) Influence de la température et de la nourriture sur la formation des castes chez Aphaenogaster senilis, (Mayr) (Hym., Formicoidea). Comptes Rendus Hebdomadaires des Séances de l'Academie des Sciences, Série D Sciences Naturelles, 284, 1899-1902.

Lenoir, A. \& Cagniant, H. (1986) Role of worker thelytoky in colonies of the ant Cataglyphis cursor (Hymenoptera: Formicidae). Entomologia Generalis, 11, 153-157.

Lenoir, A., Devers, S., Marchand, P., Bressac, C. \& Savolainen, R. (in press) Microgynous queens in the ant Manica rubida: dispersal morphs or social parasites? Journal of Insect Science.

Moritz, R.F.A. (1994) Nourishment and sociality in honeybees. Nourishment and Evolution in Insect Societies (ed. by J. H. Hunt and C. A. Nalepa), pp. 345-390. Westview Press, Boulder, Colorado.
Nonacs, P. \& Tobin, J.E. (1992) Selfish larvae: development and the evolution of parasitic behavior in the Hymenoptera. Evolution, 46, $1605-1620$

Pamilo, P. (1991) Evolution of colony characteristics in social insects. I. Sex allocation. American Naturalist, 137, 83-107.

Passera, L. (1974) Différenciation des soldats chez la Fourmi Pheidole pallidula Nyl. (Formicidae Myrmicinae). Insectes Sociaux, 21, 71-86.

Passera, L. (1980) La fonction inhibitrice des reines de la fourmi Plagiolepis pygmaea Latr.: rôle des pheromones. Insectes Sociaux, 27, 212-225.

Passera, L. \& Suzzoni, J.P. (1978) Traitement des reines par l'hormone juvenile et sexualisation du couvain chez Pheidole pallidula (Nyl.) (Hymenoptera, Formicidae). Comptes Rendus Hebdomadaires des Séances de l'Académie des Sciences, Série D Sciences Naturelles, 287, 1230-1233.

Pearcy, M., Aron, S., Doums, C. \& Keller, L. (2004) Conditional use of sex and parthenogenesis for worker and queen production in ants. Science, 306, 1780-1783.

Peeters, C. \& Ito, F. (2001) Colony dispersal and the evolution of queen morphology in social Hymenoptera. Annual Review of Entomology, 46, 601-630.

Pereboom, J.J.M. (2000) The composition of larval food and the significance of exocrine secretions in the bumblebee Bombus terrestris. Insectes Sociaux, 47, 11-20.

Pereboom, J.J.M., Velthuis, H.H.W. \& Duchateau, M.J. (2003) The organisation of larval feeding in bumblebees (Hymenoptera, Apidae) and its significance to caste differentiation. Insectes Sociaux, 50, $127-133$.

R Core Team (2008) R: A Language and Environment for Statistical Computing. Version 2.3.1. R Foundation for Statistical Computing. R Foundation for Statistical Computing, Vienna, Austria.

Ratnieks, F.L.W. (2001) Heirs and spares: caste conflict and excess queen production in Melipona bees. Behavioral Ecology and Sociobiology, 50, 467-473.

Ratnieks, F.L.W., Foster, K.R. \& Wenseleers, T. (2006) Conflict resolution in insect societies. Annual Review of Entomology, 51, 581-608.

Ribeiro, M.d.F., Santos Filho, P.d.S. \& Alves, P.d.A. (2006) Miniature queens in stingless bees: basic facts and evolutionary hypotheses. Apidologie, 37, 191-206.

Rüppell, O., Heinze, J. \& Hölldobler, B. (1998) Size-dimorphism in the queens of the North American ant Leptothorax rugatulus (Emery). Insectes Sociaux, 45, 67-77.

Schneirla, T.C. (1971) Army Ants. A Study in Social Organization (ed. by H. R. Topoff), W.H. Freeman \& Co., San Francisco, California.

Schwander, T., Humbert, J.-Y., Brent, C.S., Helms Cahan, S., Chapuis, L., Renai, E. et al. (2008) Maternal effect on female caste determination in a social insect. Current Biology, 18, 265-269.

Seeley, T.D. (1985) Honeybee Ecology. A Study of Adaptation in Social Life. Princeton University Press, Princeton, New Jersey.

Trivers, R.L. (1974) Parent-offspring conflicts. American Zoologist, 14, 247-262.

Tsuji, K. (1988) Obligate parthenogenesis and reproductive division of labor in the Japanese queenless ant Pristomyrmex pungens. Comparison of intranidal and extranidal workers. Behavioral Ecology and Sociobiology, 23, 247-255.

Tsuji, K. \& Yamauchi, K. (1995) Production of females by parthenogenesis in the ant Cerapachys biroi. Insectes Sociaux, 42, 333-336.

Vargo, E.L. \& Fletcher, D.J.C. (1986) Evidence of pheromonal queen control over the production of male and female sexuals in the fire ant, Solenopsis invicta. Journal of Comparative Physiology A, 159, 741-749.

Weir, J.S. (1959) Egg masses and early larval growth in Myrmica. Insectes Sociaux, 6, 187-201. 
Wenseleers, T., Hart, A.G. \& Ratnieks, F.L.W. (2004) When resistance is useless: policing and the evolution of reproductive acquiescence in insect societies. American Naturalist, 164, E154-E167.

Wenseleers, T., Ratnieks, F.L. \& Billen, J. (2003) Caste fate conflict in swarm-founding social Hymenoptera: an inclusive fitness analysis. Journal of Evolutionary Biology, 16, 647-658.

Wenseleers, T., Ratnieks, F.L.W., Ribeiro, M.d.F., Alves, D.d.A. \& Imperatriz-Fonseca, V.L. (2005) Working-class royalty: bees beat the caste system. Biology Letters, 1, 125-128.

Wheeler, D.E. (1986) Developmental and physiological determinants of castes in social Hymenoptera: evolutionary implications. American Naturalist, 128, 13-34.

Wheeler, D.E. (1994) Nourishment in ants: patterns in individuals and societies. Nourishment and Evolution in Insect Societies (ed. by
J. H. Hunt and C. A. Nalepa), pp. 245-278. Westview, Boulder, Colorado.

Winston, M., Higo, H.A. \& Slessor, K.N. (1990) Effects of various dosages of queens mandibular gland pheromone on the inhibition of queen rearing in the honey bee (Hymenoptera: Apidae). Annals of the Entomological Society of America, 83, 234-238.

Winston, M.L. (1987) The Biology of the Honey Bee. Harvard University Press, Cambridge, Massachusetts.

Accepted 24 April 2009

First published online 5 June 2009 